\title{
Una carga para los pobladores y un desafió para las autoridades: el abastecimiento de los ejércitos en el suroccidente neogranadino durante las guerras de 1808-1824*
}

David Fernando Prado Valencia

Profesor catedrático del departamento de Historia de la Universidad del Cauca (Colombia) e integrante del grupo de Investigación Estado Nación: Instituciones y organizaciones de la misma institución. Correo electrónico: davidprado@unicauca.edu.co. El autor es Magíster en Historia Universidad del Valle (Colombia). Entre sus publicaciones reciente esta: "Las mutaciones del Cabildo de Popayán en un periodo revolucionario, 1809-1811”, Anuario Colombiano de Historia Social y de la Cultura Vol. 47 No. 1 (2020). Su tema de interés es Historia política y militar en la era de las revoluciones.

\section{Christian Camilo Valencia Colina}

Afiliado institucionalmente a la Universidad del Cauca (Colombia). Integrante del semillero de investigación Estado Nación: Instituciones y organizaciones de la misma institución. Correo electrónico: camivaco@ unicauca.edu.co. El autor es Historiador de la Universidad del Cauca (Colombia). Su tema de interés es Historia política y militar en la era de las revoluciones.

Recibido: 30 de marzo de 2019

Aprobado: 10 de noviembre de 2019

Modificado: 20 de noviembre de 2019

Artículo de investigación científica

DOI: http://dx.doi.org/10.15648/hc.36.2020.4

Este artículo forma parte del proyecto "Guerra y política en la independencia del suroccidente neogranadino" financiado por la Universidad del Cauca (Colombia).

Esta publicación está bajo una licencia Creative Commons Reconocimiento-NoComercial 4.0 
Una carga para los pobladores y un desafió para las autoridades: el abastecimiento de los ejércitos en el suroccidente neogranadino durante las guerras de 1808-1824

\title{
Resumen
}

El presente artículo tiene como objetivo analizar el abasto militar durante el periodo independentista en la provincia de Popayán. En la primera parte exponemos el tipo de productos requeridos por las tropas y las estrategias empleadas por las autoridades para extraerlos de la población. En la segunda parte describimos el organigrama institucional del abasto, su funcionamiento, sus particularidades y las tensiones que a veces provocaba en cada instancia por la cual transitaban las mercancías remitidas a las tropas. En la tercera y última parte se analizan las experiencias de algunos funcionarios y vecinos que estuvieron comprometidos en las tareas de vestir y alimentar las tropas.

Palabras clave: Revolución, Abasto militar, Ejércitos, Logística, Experiencia, Provincia de Popayán.

\section{A burden for the inhabitants and a challenge for the authorities: armies' supplying in New Granada southwestern during the wars of 1808-1824}

\begin{abstract}
The purpose of this article is to analyze the military supply during war conflicts caused by the change of regime from monarchical to republican in the province of Popayán. First of all, it is presented the type of products required by the troops and the strategies the authorities employed to obtain them from population of all social classes. In the second part we describe the institutional organization chart of the supply and its operation, pointing out the particularities and tensions generated in every instance the goods sent to the troops went through. The third and last part analyzes the changes that the supply generated in the experience of several officials and neighbors, who were involved in the tasks of supplying the troops for whom the revolution and the war marked new and unexpected contours to their life cycles.
\end{abstract}

Keywords: Revolution, Military supply, Armies, Logistics, Experience, Province of Popayán. 
Um fardo para os moradores e um desafio para as autoridades: o aprovisionamento dos exércitos no Sudoeste da Nova Granada durante as guerras entre 1804 a 1824

\section{Resumo}

O seguinte artigo tem como objetivo analisar o abastecimento militar durante o período de independência na província de Popayán. Na primeira parte, explicarmos o tipo de produtos requeridos pelos militares e as estratégias usadas pelas autoridades para extraí-los da população. Na segunda parte, descrevermos o fluxograma institucional do suprimento, seu funcionamento, suas particularidades e as tensões que às vezes causava quando os bens eram enviados às tropas. A terceira e última parte analisa as experiências de alguns oficiais e habitantes envolvidos nas tarefas de vestir e alimentar os soldados.

Palavras-chave: Revolução, Abastecimento Militar, Exércitos, Logística, Experiência, Província de Popayán.

\section{Un fardeau pour les habitants et un défi pour les autorités:}

\section{l'approvisionnement des armées dans le sud-ouest néo-grenadin pendant} les guerres de 1808-1824

\section{Résumé}

Cet article vise à analyser l'approvisionnement militaire pendant la période d'indépendance dans la province de Popayán. Dans la première partie, nous présentons le type de produits dont les troupes ont besoin et les stratégies utilisées par les autorités pour que la population les leur fournisse. Dans la deuxième partie, nous décrivons l'organigramme institutionnel de l'approvisionnement, son fonctionnement, ses particularités et les tensions provoquées chaque fois que les marchandises étaient envoyées aux troupes. La troisième et dernière partie analyse les expériences de certains fonctionnaires et voisins engagés dans les tâches d'habillement et d'alimentation des troupes.

Mots-clés: Révolution, Approvisionnement militaire, Armées, Logistique, Expérience, Province de Popayan. 


\section{INTRODUCCIÓN}

El 4 de junio de 1808, el cabildo de Popayán remitió al gobernador de su provincia un informe detallado sobre el número de vecinos en edad de tomar las armas, su destreza para manejar el sable y lo poco adiestrada que era la población para usar la escopeta o el fusil, agregando que "desde las batallas que hubieron, entre los conquistadores, y los Indios, no hay memoria de otras en esta jurisdicción. [...] La tranquilidad, sumisión, y obediencia, de los moradores de esta provincia, todo ha contribuido a que jamás, haya visto, la desolación, ni la muerte, ni los horrores de una batalla. La voz de un juez y bastante a contener cualesquier desorden [sic] y jamás ha habido la sublevación ni alborozo que llegue a las armas" . Con estas apreciaciones el gobernador descartaba que su jurisdicción se viera envuelta en una conflagración militar². Un año después, cuando las tropas de la Junta Soberana de Quito ingresaron al sur de la provincia, Tacón comprendió que el pasado dejaba de ser un lente fiable para evaluar posibles amenazas bélicas, puesto que el presente resquebrajaba con hechos concretos el antiguo panorama militar de su jurisdicción forzándolo a armar un ejército para combatir a las "falanges quiteñas".

Desde 1809, la población que habitaba la provincia de Popayán enfrentó las inéditas experiencias bélicas y la militarización de la vida colectiva. En el caso de los territorios de la provincia de Popayán los combates fueron una situación muy recurrente en todas las localidades cuya población debió abastecer de alimentos y vituallas a los ejércitos que fueron a las armas en defensa de un régimen político tanto realista como republicano. El objetivo de este artículo es estudiar el abastecimiento de las tropas cuando uno u otro sector enfrentado controló las instituciones vigentes, o las que se fueron creando en el curso de la revolución. Alimentar y vestir las tropas era una garantía para evitar las deserciones, mantener el orden y la cohesión de los cuerpos armados y evitar aún mayores tensiones entre los militares y el resto de la población que padeció la presión de abastecerlos incluso dentro de circunstancias en las que la escasez primaba entre la mayoría de los vecinos ¿Cuáles fueron las estrategias de las autoridades para extraer de la población alimentos

\footnotetext{
1 Archivo central del Cauca (En adelante A.C.C.) Libros Capitulares, Tomo 53, 1808, f. 57r.

2 Archivo Histórico de Cali (En adelante A.H.C.), Libros Capitulares, Tomo 37, 1801 -1810, f. 280v.
} 
y vituallas para las tropas? ¿Qué tipo de productos hicieron parte de la dieta militar? ¿Cómo se organizó la recolección y entrega de los suministros? ¿Cómo el abasto fue experimentado por los vecinos de localidades y sitios? El esclarecimiento de estas preguntas en la provincia de Popayán durante 1808 a 1824 es el marco en el cual desarrollamos el presente texto. Las fuentes estudiadas son en su mayoría recibos, oficios, pliegos y cartas de origen institucional, en ellas se encuentran los registros de abastecimiento para los ejércitos realistas y republicanos, el uso que estos le dieron a instituciones monárquicas como el cabildo, además de consignar la aparición de nuevos funcionarios como el proveedor, quien fue el jefe encargado de articular a todos los funcionarios comprometidos con sostener el envío de suministro necesarios.

Este campo de investigación ha sido atendido por diversos historiadores en Latinoamérica. Por ejemplo Abel Fernando Martínez y Andrés Ricardo Otálora estudian las dificultades del clima y del territorio como elementos que complejizaron las expediciones en las que se jugó la victoria o la derrota de las tropas ${ }^{3}$. Yoer Castaño analiza las diversas formas de alimentación de los militares en las ciudades describiendo el sistema de "ranchos" en tiempos de conflicto y resaltando la práctica del abigeo como una acción recurrente para suministrar carne a los ejércitos ${ }^{4}$. Ambos trabajos son interesantes porque abordan los conflictos sociales y políticos que genera el abasto, sin llegar a especificar qué productos son los enviados a los hombres en armas. Luis E. Prado señala que los obstáculos para la alimentación y la movilización de las tropas fueron estructurales debido a las pocas vías de comunicación y la ausencia de personal calificado capaz de asumir este tipo de tareas que no se habrían logrado solucionar sin la cooperación de la población ${ }^{5}$. Cristina Mazzeo interpreta el abastecimiento de tropas en el Perú como un hecho en el cual confluyen la guerra, la sociedad y la economía, destacando el papel

3 Abel Fernando Martínez Martin, y Andrés Ricardo Otálora Cascante, "Hambriento un pueblo lucha. La alimentación en los ejércitos del Rey y del Libertador durante la independencia de Colombia (1815-1819)", Historia Crítica No. 41 (2010): 86-109.

4 Yoer J Castaño P, "Alimentación y abastecimiento de víveres entre las tropas patriotas de la Nueva Granada, 1811-1816", Anuario de Historia regional y de las fronteras, Vol. 9 No. 1 (2004): 95-112.

5 Luis Ervin Prado Arellano. "Organización y logística: los límites para la organización del ejército neogranadino en contienda”, Historia y Espacio, No. 24 (2005): 1-20. 
de los comerciantes en el desarrollo de dicha actividad ${ }^{6}$. Un trabajo de Alejandro M. Rabinovich ofrece una perspectiva microhistórica sobre el soldado; se distancia de los ya referidos autores al enfocar su atención en la experiencia de las tropas que padecieron hambrunas que en algunos casos estimularon el suicidio de los militares, estas las situaciones extremas exigieron a los oficiales estar atentos a subsanar la escasez tan pronto empezaban a levantarse algunos reclamos ${ }^{7}$. Los estudios mencionados ofrecen desde distintas ópticas una interpretación sobre el abasto militar, un objetivo que compartimos, pero que tratamos de explorar integrando tres dimensiones: la dieta militar, la logística institucional que la hizo posible y la experiencia de algunos funcionarios y vecinos que estuvieron involucrados en esta actividad.

En la primera parte de este artículo presentamos las estrategias de extracción de moneda, carne, sal, harina y aguardiente entre otros productos que fueron obtenidos de la población, configurando una economía de guerra que le da prelación al abasto militar y por ende deja en estado de subordinación a las instituciones de gobierno y las necesidades de la población. Esta situación exigió a las autoridades tácticas que combinaron la legalidad con la coacción y el esfuerzo por afectar lo menos posible a los hacendados, comerciantes y gentes del común sobre quienes recayó la labor de alimentar y vestir a los soldados. En la segunda parte exponemos la logística empleada para mover los alimentos y vituallas de la población a las tropas; una exploración deja en evidencia cómo los ejércitos toman las instituciones vigentes y crean nuevas autoridades para ordenar y hacer cumplir la recolección y distribución del abasto militar. Finalmente analizamos las tensiones que generó la economía de guerra, las trasformaciones que ésta estimuló en instituciones como el cabildo, además de las experiencias que tuvieron algunos vecinos que desempeñaron funciones en la extracción y envío de recursos para los cuerpos armados.

6 Cristina Mazzeo "Pagando por la guerra: comercio y finanzas. Entre la independencia y la Guerra de la Confederación”, en Tiempo de guerra. Estado, nación y conflicto en el Perú, siglos XVII- XIX, eds. Carmen MacEvoy, Alejandro Rabinovich (Lima: Instituto de Estudios Peruanos, 2018), 191 - 21.

$7 \quad$ Alejandro Rabinovich, Ser soldado en las guerras de Independencia. La experiencia cotidiana de las tropas en el Río de la Plata, 1810- 1824 (Buenos Aires: Random Hause Mondadori, 2013), $53-61$. 


\section{Alimentos, vestidos, monedas: el abasto y las estrategias de EXTRACCIÓN.}

La ración diaria entregada a las tropas estaba supeditada al suministro que fuera posible obtener, pero básicamente incluyó carne, sal, plátanos, arroz, papas, amasijos y aguardiente. La carne fue un producto constante dentro de la alimentación de las tropas que recibían su ración en libras de acuerdo al rango militar ${ }^{8}$; la proteína animal dentro de los ejércitos también estaba destinada a pagar los servicios de postas y acarreadores?. Después de distribuir la carne, las partes que no se repartían eran vendidas entre la población donde acampaban las tropas ${ }^{10}$. La alimentación a base de carne en Popayán ya era bastante alta antes de la guerra, pero la alimentación de las tropas elevó aceleradamente la demanda al punto de devastar la producción ganadera de la provincia pues todos los estamentos de la sociedad fueron obligados a contribuir suministrando reses de acuerdo a su jerarquía y posesión de ganados ${ }^{11}$.

Los plátanos fueron el segundo producto de mayor consumo, solo la proveeduría de Buga llegó a suministrar 75.953 unidades, la satisfacción de esta alta demanda trató de solucionarse mediante el trabajo de algunos oficiales que sembraron cultivos exclusivos para las tropas ${ }^{12}$. Comer arroz o papas fue más bien un deleite excepcional que estuvo determinado por las posibilidades del proveedor para comprar algunas arrobas; en otras ocasiones dichos alimentos llegaban a las tropas como resulta-

8 "Raciones de carne entregadas en Ovejas" (Campo de Ovejas, 31 de mayo - 31 de junio de 1822), ACC, Fondo Independencia - Militar, Correspondencia, Sig. 1233, Ind. MI-2ab f.1r-2v.

9 "Carta de Ignacio Rengifo en donde expresa la cantidad de carne entregada al portador de un vale" (Cali, 9 de octubre de 1821), ACC, Fondo independencia - Militar. Correspondencia. Sig. 1228 Ind. MI -2 ad f.13r.

10 El Palo (30 de diciembre de 1820), ACC, Fondo independencia - Militar. Correspondencia. Sig. 1080 Ind. MI - 2 ad f.17r. "Cuenta realizada por el proveedor José María Otero de la carne vendida en su proveeduría" (Obejas, 9 de febrero - 10 de abril 1822), ACC, Fondo independencia - Militar. Correspondencia. Sig. 1283 Ind. M I - 8 ad f.1r-4v.

11 Santa Ana (19 de octubre de 1820), ACC, Fondo independencia - Militar. Correspondencia. Sig. 1063 Ind. MI - 2ad f.1r. "Lista de ganados remitidos y recibidos en Popayán por el Alcalde de Caloto Thomas Fernández” (Quilichao, 24 de octubre de 1821 - 12 de mayo de 1822) ACC, Fondo independencia- Militar. Correspondencia. Sig. 1227 Ind MI - 2ad f. 1r -1v.

12 "El comandante realista Juan José Vejarano sembró en Anchicayá 1.000 plantas" (Buga 1 de noviembre- 31 de diciembre de 1821), ACC, Fondo independencia - Militar. Correspondencia. Sig. 1078 Ind. MI -2 ad f.13v. (La Cruz, 26 de agosto de 1815), ACC, Fondo independencia - Militar. Correspondencia. Sig. 310 Ind. M I -2 ad f.21v. 
do del embargo ${ }^{13}$. Un producto como la harina exigía la contratación de varias panaderas para hornear galletas y pan. Por ejemplo, entre mayo y junio de 1818, nueve mujeres cocinaron 1.200 arrobas de amasijos para el Batallón Numancia acantonado en Popayán ${ }^{14}$. De manera excepcional el basto podía llegar a incluir aguardiente que era suministrado a los militares antes de iniciar una batalla ${ }^{15}$. Al parecer el alto consumo de carne o la preparación de menestra explica la constante demanda de sal para los soldados ${ }^{16}$. Las vituallas para los ejércitos eran principalmente camisas, pantalones, chaquetas, capisayos, alpargatas, cachuchas y cobijas para las tropas que ascendían a zonas de clima frio $^{17}$.

Que los ejércitos obtuvieran oportunamente comida y vituallas era un desafío para las autoridades que debían tomar estos artículos de la población o adquirirlos en los mercados locales lo que hizo indispensable para los oficiales contar con dinero suficiente para sostener los requerimientos del abasto. La moneda fue el recurso más absorbido a los vecinos a través de tres estrategias: empréstitos, capitaciones y donativos. Los empréstitos tuvieron dos modalidades: regulares y nominales. Los primeros son los que pagan los vecinos con dinero, ganados u otros productos que son entregados a las autoridades en calidad de préstamo bajo la promesa de que luego sería saldada la deuda por el gobierno. Durante el desplazamiento de las tropas las autoridades civiles decretaron un empréstito que en algunos casos era cancelado de manera volun-

13 "Vale a favor del proveedor por ocho raciones de carne sal arroz para los soldados" (Ovejas, 3 de octubre de 1821), ACC, Fondo independencia - Militar. Correspondencia. Sig. 1067 Ind. MI - 2 ad f.2r. (Buenaventura,13 de mayo de 1820), ACC, Fondo independencia - Militar. Correspondencia. Sig. 965

14 (Popayán 01 de mayo 1818), ACC, Fondo independencia - Militar. Correspondencia. Sig. 694 Ind. MI - 2 ad. f.3r.

15 José María Espinoza, Memorias de un abanderado; recuerdos de la Patria boba 1810 - 1819. (Bogotá: Editorial Minerva S. A, 1936), 72 y 93. (Cali, 8 de junio de 1821), ACC, Fondo independencia - Militar. Correspondencia. Sig. 1157 Ind. M I -2 ad f.12r.

16 "Vale a favor del proveedor por ocho raciones de carne, sal, arroz para los soldados" (Ovejas, 3 de octubre de 1821), ACC, Fondo independencia - Militar. Correspondencia. Sig. 1067 Ind. MI - 2 ad f.6r. (Quilichao 2 - 18 de octubre de 1821), ACC, Fondo independencia - Militar. Correspondencia. Sig. 4957 Ind. MI - 10 ad f. 3r - 55v. (Quilichao, 20 - 30 de enero de 1822), ACC, Fondo independencia - Militar. Correspondencia. Sig. 1229 Ind. MI - 2 ad f. $3 r-33 r$. Ind. MI - 8ad f.3v. "Partida de cargo a la comisaría de vestuarios hechas por Lorenzo Camacho" (Cali 12 de marzo de 1821) ACC, Fondo independencia - Militar. Correspondencia. Sig. 6886 Ind MI - 11ad f.1r. 
taria y en otros casos bajo presión ${ }^{18}$. Documentos oficiales como vales de deuda y libros de empréstitos pagados dejan en evidencia el carácter legal de esta modalidad y el esfuerzo de las autoridades por regular la recolección para del abasto militar ${ }^{19}$. Por otro lado, los segundos fueron deducciones a los salarios de los militares con el objetivo de comprar ropas, armas o sufragar el hospital militar y el monte pío de inválidos ${ }^{20}$. La capitación recaudaba dinero o alimentos sobre la base de los avalúos hechos a las propiedades de los vecinos. Su cobro iniciaba cuando las autoridades militares asignaban a una jurisdicción una cantidad de dinero a pagar, luego el cabildo de la localidad determinaba quiénes eran aptos para ser gravados y entre los seleccionados se distribuía el monto de acuerdo a los bienes y posesiones particulares ${ }^{21}$.

Por último, los donativos se aplicaron desde el inicio de la crisis monárquica en 1808 hasta varios años después de la instauración de la república.

Seguir el rastro a los donativos devela la fuerza trasformadora de la revolución que modificó las formas y discursos en torno a esta estrategia para obtener recursos destinados al abasto. Por ejemplo, en 1808 el cabildo solicitó un donativo para financiar a los ejércitos que combatían a las tropas francesas; en dicha oportunidad la recolección y registro con-

18 "Relaciones de las deudas pagadas a los acreedores de empréstitos que se han exigido en la provincia pagados en la caja de Cartago" (Cundinamarca, 20 - 29 de diciembre de 1820), ACC, Fondo independencia-Militar. Correspondencia. Sig. 2405 Ind. CI - 23cp. f. 1r. (Caloto, 31 de enero de 1815), ACC, Fondo independencia - Militar. Correspondencia. Sig. 440 Ind. CI - 1cp. f. 1v. "Empréstito cobrado por Atanasio Bonilla a la ciudadana Rosalía Mosquera por razón de diez patacones, diez y siete reales" (Alegrías, 5 de febrero de 1815), ACC, Fondo independencia - Militar. Correspondencia. Sig. 440 Ind. CI - 1cp. f. 2r. "Cuaderno en donde se asientan las partidas de los vecinos de Quilichao y las contribuciones mandadas en calidad de empréstitos por los propietarios de ganado" (Caloto, 25 de enero de 1815), ACC, Fondo independencia - Militar. Correspondencia. Sig. 440 Ind. CI - 1cp. f.1r - 4r.

19 "Lista elaborada por Atanasio Bonilla a razón de referir todos los vecinos que contribuyeron ganados y otros menesteres en forma de empréstitos para el mantenimiento de las tropas" (Caloto, 25 de enero de 1815), ACC, Fondo independencia - Militar. Correspondencia. Sig. 440 Ind. C I -1

20 "Descuentos por nomina en calidad de empréstito hechos al ejército" (Popayán, 1 de enero - 15 de febrero de 1814), ACC, Fondo independencia - Militar. Correspondencia. Sig. 6310 Ind MI - 11ad f.1v. (Cali, 15 de mayo de 1816), ACC, Fondo independencia - Militar. Correspondencia. Sig. 500 Ind. M I -2 ad f.10r. "Recibos entregados por los ministros de hacienda a diferentes militares para el mantenimiento del cuartel y las tropas" (Cali, del 10-26 de mayo 1816), ACC, Fondo independencia - Militar. Correspondencia. Sig. 500 Ind. M I -2 ad f.7R - 15v.

21 "Cuenta de la cantidad entregada por el partido del Pescado a los alcaldes ordinarios saldando la deuda correspondiente al ramo de capitación, en esta cuenta se encuentra la cantidad suministrada por los vecinos del lugar" (Cali, 9 de enero de 1821), ACC Fondo independencia - Militar. Correspondencia. Sig. 1105 Ind. CI - 15cp f.1r. "Lista de los individuos que contribuyeron con la capitación exigida y graduada por el vicepresidente del departamento" (Morillo, 10 de enero de 1821), ACC, Fondo independencia - Militar. Correspondencia. Sig. 6732 Ind CIII-6cg f.1r. 
table se realizó por estamentos ${ }^{22}$, además el recaudo entre los sectores plebeyos fue encargado a un regidor acompañado por frailes que debían explicar la obligación moral de todo cristiano en ayudar a sostener las tropas que defendían al rey y a la religión ${ }^{23}$. Doce años después, derruido ya el régimen monárquico, las autoridades realizaron un donativo recogiendo los recursos sin segregar el registro en estamentos, agrupado a todos los contribuyentes en una sola lista con el título de ciudadanos ${ }^{24}$.

Para las autoridades, de las tres formas de obtener recursos, la capitación era la modalidad menos onerosa para la población porque los vecinos ocultaban bienes durante los avalúos ${ }^{25}$. En las capitaciones, empréstitos y donativos el cabildo se encargó de ordenar los cobros, llevar la contabilidad y fiscalizar la recolección del dinero como su distribución. A pesar de los controles llevados por las autoridades capitulares, hubo situaciones en que los militares pasaron por alto el marco legal expropiando sin cumplir las formalidades estipuladas. Esto explica por qué en 1819 en la provincia de Popayán el gobernador Pedro Domínguez trató de subsanar los atropellos a los vecinos reglamentando casuísticamente todas las actividades relativas al abasto militar ${ }^{26}$.

Los empréstitos y las capitaciones aplicadas sobre la población de la provincia de Popayán hicieron parte del marco legal de una economía de guerra que arruinó a las haciendas y desajustó el circuito económico que las articulaba con los yacimientos de oro ubicados en el andén del Pacífico ${ }^{27}$. Debido los pocos alimentos en las plazas de mercado, las autoridades ordenaron a los comerciantes vender primero a las tropas y luego a los demás vecinos dejando en evidencia el peso del abasto militar que la guerra puso sobre los vecinos de la provincia de Popayán.

22 (17 de noviembre de 1808), ACC, Acta del Cabildo de Popayán, f. 51r - 52r.

23 (1808), ACC, Libros Capitulares, t.53, f.29v.

24 "Lista de los individuos que contribuyeron en calidad de donativo" (Popayán, 18 de febrero de 1820), ACC, Fondo independencia - Militar. Correspondencia. Sig. 946 Ind CI -16h f.1r-3v.

25 Carta enviada por Francisco de Paula Santander al libertador Simón Bolívar en donde se expresa la necesidad de recaudar dineros utilizando cualquier método para lograrlo. Bogotá 16 de mayo de 1820. Luis Horacio López Domínguez. Cartas Santander - Bolívar 1820. Tomo II (Bogotá: Fundación para la conmemoración del bicentenario del natalicio y el sesquicentenario de la muerte del general Francisco de Paula Santander, 1988), 140.

26 "Oficio del gobernador Pedro Domínguez" (Popayán, julio 17 de 1819) Archivo Cipriano Rodríguez Santa María (AHCRSM), Caja 28, carpeta 3, f.17r.

27 Luis E. Prado, "Esclavismo, consenso y rebelión en la costa pacífica neogranadina, 1810-1830, en El siglo XVIII americano, eds., Ana Catalina Reyes, Juan David Montoya, Sebastián Gómez González, (Medellín: Universidad Nacional de Colombia, sede Medellín, 2013), 255- 282. 


\section{El CICLO DE ABASTECIMIENTO MILITAR Y SU ORGANIGRAMA EN TIEMPOS DE GUERRA.}

La logística del abastecimiento involucró funcionarios y vecinos, todos equiparados con el mismo nivel de importancia, pues el efectivo desempeño de cada uno aseguraba que las solicitudes de los oficiales militares fueron sufragadas a satisfacción en el menor tiempo posible. En otras palabras, en la logística del abasto es tan importante el posta o paje que conduce las reses, la panadera que cuece la harina o el proveedor que ejerce como la autoridad que coordina el proceso del suministro militar. Si uno de los involucrados falla, el engranaje logístico se detiene desencadenando tensiones entre los militares, las autoridades y la población.

Organigrama institucional del abasto

Provincia de Popayán 1808- 1824

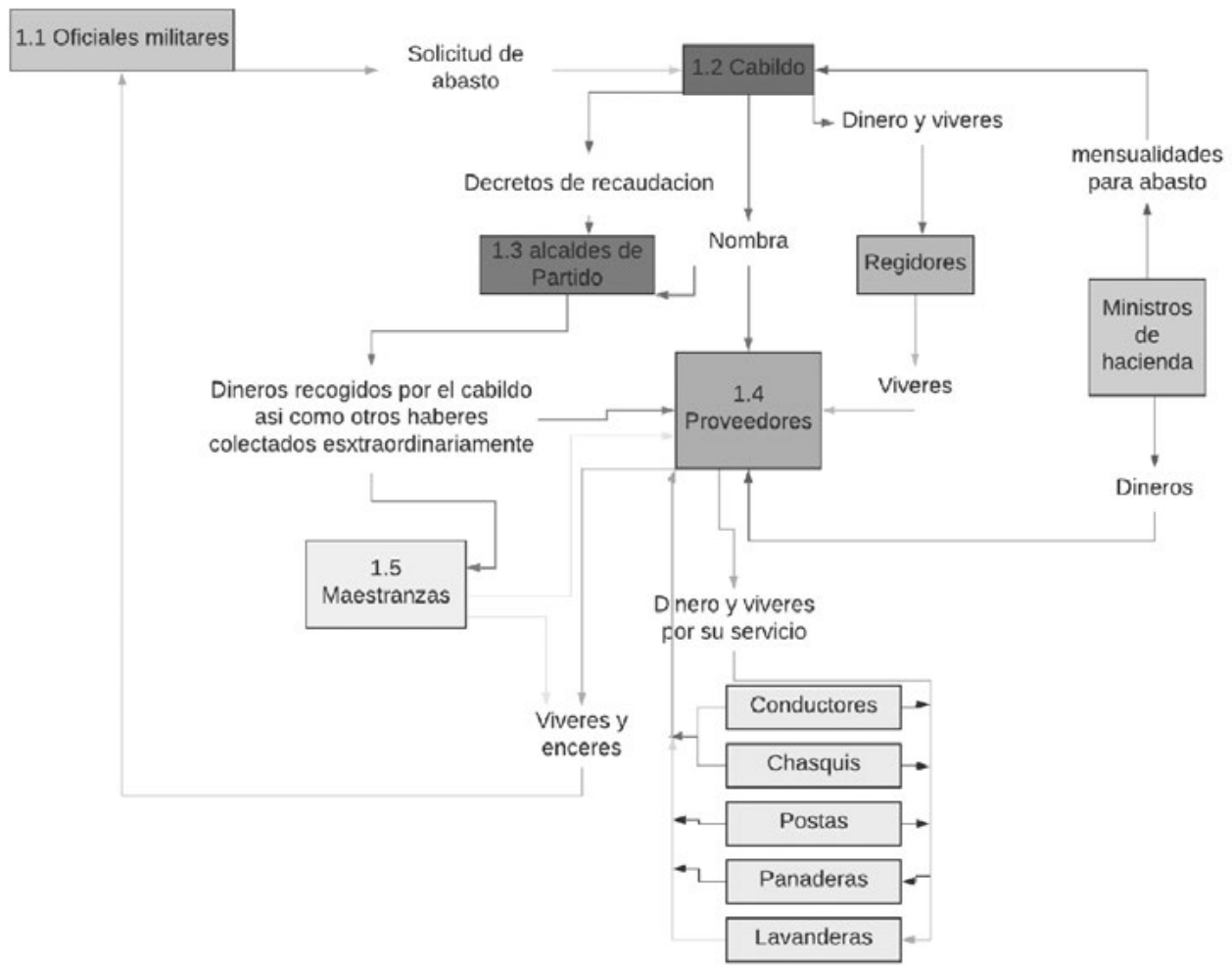

Fuentes: ACC, Fondo independencia - Militar. Correspondencia. Sig. 3364 Ind. M I -10 ad f.5r. ACC, Actas de Cabildo de Popayán para el año de 1817, t. 58, ff.7r -7v; 71r -71v. ACC, Fondo independencia - Militar. Correspondencia. Sig. 2405 Ind. CI - 23cp. f. 2 r. 
¿Cómo opera el abasto militar? el trámite arranca con la remisión de las solicitudes hechas por los oficiales a los cabildos cuyas autoridades quedaron supeditadas a los oficiales modificando sustancialmente sus funciones que pasaron de asuntos de gobierno local a garantizar la recolección de recursos a través de los instrumentos legales diseñados para extraerlos de la población ${ }^{28}$. En el organigrama del abasto, el cabildo fue el organismo que decretó los empréstitos, donativos y capitaciones y llevó los registros contables del dinero entregado por los vecinos y por las cajas reales ${ }^{29}$. La ascendencia del mando militar sobre las autoridades locales fue evidente el 4 de febrero de 1814 cuando el comandante Antonio Nariño hizo la solicitud de un empréstito a cargo del gobierno de Cundinamarca, por valor de cien mil pesos, otorgando cinco días de plazo para que se le pagara. El cabildo tomó las medidas, pero no logró reunir la cantidad expresada lo que generó una fuerte tensión entre las autoridades y el comandante en jefe que decidió reunir a vecinos acaudalados de ambos sexos. Nariño presionó a contribuir a aquellos que no accedían a pagar obligándolos a ir a sus casas escoltados de soldados hasta consignar el dinero asignado; igualmente la coacción a las comunidades religiosas las obligó a entregar alhajas de los templos para que fueran fundidas para tallar monedas, todas estas medidas las tomaron exclusivamente los militares sin consultar a las autoridades civiles ${ }^{30}$.

La jurisdicción de los cabildos incluía sitios y parroquias distantes de los emplazamientos urbanos donde el gobierno local administraba justicia

28 "Carta de Francisco Gregorio de Angulo a los honorables miembros del cabildo, recordándoles su responsabilidad frente al abasto, según orden superior del excelentísimo señor general en jefe" (Popayán, 3 de junio de 1817), ACC, Libros capitulares, t. 58, 1817. f. 29r-29v.

29 "Lista de individuos a quienes se les devolvió lo prestado en calidad de empréstito en Cundinamarca", $(20-29$ de diciembre de 1820), ACC, Fondo independencia - Militar. Correspondencia. Sig. 2405 Ind.C I - 23 cp. f. 1v. "Oficios entregados a los ministros de hacienda con el fin de que estos, por orden del Gobernador Arboleda dieran el dinero necesario para comprar galletas, carnes y otros efectos que el jefe de la escuadra había Guillermo Baran había solicitado" (Cali, 10 -15 de junio de 1816), ACC, Fondo independencia - Militar. Correspondencia. Sig. 503 Ind. M I - 2 ad f.5r - 6v. "Oficio en el que los señores del Cabildo dan constancia de los cuatrocientos sesenta y dos pesos, entregados por los ministros de hacienda para el reparto a cada uno de los individuos que conforman la tropa" (Cali, 8 de mayo de 1816), ACC, Fondo independencia - Militar. Correspondencia. Sig. 500 Ind. MI -2 ad.f. $1 \mathrm{r}-4 \mathrm{r}$.

30 "Documentos relativos al empréstito de cien mil pesos, exigidos por el general Don Antonio Nariño, al vecindario de Popayán" febrero de 1814. En: Popayán. Popayán, Año III, No. XXXIXXXXV (julio 1910): 571 - 578. AHCRSM, Fondo David Mejía Velilla, CA28-CP03- f. Grv. 
a través de los alcaldes de partido o pedáneos que eran electos anualmente. Dichos alcaldes se encargaron de comunicar a los pobladores la modalidad de contribución determinada por el cabildo, recolectarlo y coaccionar a los vecinos morosos ${ }^{31}$. Los alcaldes de partido fueron esenciales para la recolección de ganados debido a que los potreros de seba se encontraban por lo general bajo su jurisdicción; a esta tarea se sumó la obligación de llevar un libro de cuentas de lo percibido y entregado a los cabildos o directamente al proveedor ${ }^{32}$.

Por las necesidades de la guerra apareció un nuevo tipo de funcionario, el proveedor, quien era nombrado por el cuerpo capitular y su función consistía en coordinar la entrega del abasto a los militares. Los designados por las autoridades realistas para desempeñar dicha función fueron vecinos acaudalados que simpatizaron con la revolución, ellos además de tener responsabilidades contables, debían asumir a veces de sus propio peculio el pago de alimentos y vituallas, lo que explica sus constantes solicitudes de relevo o su esfuerzo por eludir dicha responsabilidad $^{33}$. En el organigrama del abasto el proveedor fue un eslabón entre el cabildo y los militares, lo que por un lado lo hizo un funcionario dependiente del cabildo que era la única autoridad que podía nombrarlo o reemplazarlo y por otro fue un subalterno a los oficiales. En síntesis, en el ciclo de abastecimiento el proveedor padeció una presión del cabildo que lo nombraba en retaliación a sus opiniones políticas y de los militares que lo coaccionaban incluso violetamente cuando se tardaban en llegar los recursos a las tropas. El 14 de marzo de 1822 José María Troches que se encontraba en el sitio de Ovejas fue visitado por los oficiales acantonados en Quilichao exigiéndole la entrega de suministros, porque un rumor aseguraba que ya le habían llegado a su dependencia. $\mathrm{Al}$ no tener alimentos que proporcionar fue zaherido por los oficiales;

31 (Buga, 24 de septiembre de 1820), ACC, Fondo independencia - Militar. Correspondencia. Sig. 1108. Ind. C I -15 cp. f.5r

32 (Popayán, 10 de septiembre de 1816), ACC, Actas de Cabildo para el año de 1815 - 1816. t. 57. f.48v.

33 (Ovejas, 27 de septiembre - 2 de noviembre de 1821), ACC, Fondo independencia - Militar. Correspondencia. Sig. 1067 Ind. MI -2 ad f. 1r-3r. 
después de esta situación Troches exigió ser relevado de su cargo, sino le llegaba el abasto ${ }^{34}$.

En el ciclo del abasto la maestranza era central por ser el local responsable de la confección de uniformes y la refacción de armas, actividades realizadas por sastres, costureras, artesanos y plateros ${ }^{35}$. Esta producción de vituallas tomó relieve durante la restauración monárquica, período en el que el batallón Numancia se acuarteló en Popayán. En el engranaje del abastecimiento se incluyó a otros vecinos por fuera de la maestranza como conductores, postas, peones y panaderas que trabajaron cooperando con las tareas de suministrar servicios y recursos al ejército. La carne que fue el alimento más consumido por los ejércitos realistas y patriotas exigió el movimiento de decenas de ganados por el territorio. Al norte de la provincia en un solo mes las tropas en Caloto recibieron trescientas cabezas de ganado, cien remitidas desde el Palo y doscientas desde Cali ${ }^{36}$. Los conductores recibían un pago en moneda y una ración igual a la de las tropas, lo que ejemplifica una actividad económica que generó el abastecimiento en las ciudades y campos de la provincia ${ }^{37}$. La correspondencia es de vital importancia para el gobierno y la dirección de la guerra una tarea desempeñada por postas y "chasquis" que igualmente fueron pagados en moneda y especie ${ }^{38}$.

El que las tropas se alimentaran regularmente con los recursos que le entregaban los proveedores fue el ciclo ideal que desde luego tuvo ex-

34 (Ovejas, 14 de marzo de 1822), ACC, Fondo independencia - Militar. Correspondencia. Sig. 3364 Ind. M I -10 ad f. 5 r.

35 ACC, Libros Capitulares, t. 58, 1817. f. 56r- 56 v. "Carta de Cayetano Espinoza en donde le pide razón de los vestuarios elaborados para los ejércitos del sur” (Popayán, 4 de agosto de 1820), ACC, Fondo independencia - Militar. Correspondencia. Sig. 6536 Ind. CII - 23h f.9r.

36 "Carta de Miguel José Barona enviada al señor alcalde ordinario Nicolás de Silva, con el fin de dar razón de los ganados colectados por orden del gobierno" (Campo del Palo, 29 de diciembre de 1820), ACC, Fondo independencia - Militar. Correspondencia. Sig.1008 Ind. M I -2 ad f.1r. ACC Fondo independencia - Militar. Correspondencia. Sig.1008 Ind. M I -2 ad f.1r.

37 "Vales a favor de militares, en donde se constata lo dado a los conductores para su alimentación" (Quilichao, 1 - 24 de octubre de 1821), ACC, Fondo independencia - Militar. Correspondencia. Sig. 4957 Ind. MI - 10 ad f.32r - 43.v. ACC Fondo independencia - Militar. Correspondencia. Sig. 694 Ind. M I - 2 ad. f.3r.

38 "Cuenta de cargo y data que el alcalde partidario Andrés Saa presentó al señor alcalde ordinario Tomas Fernández del ganado que entro a esa provincia" (Quilichao, 20 de enero -5 de febrero de 1822), ACC, Fondo independencia - Militar. Correspondencia. Sig. 1229 Ind. M I -2 ad. f.1r. 
cepciones. Cuando las tropas no obtenían raciones de alimento, los soldados compraban comida a crédito. Esta situación atentaba contra la disciplina de la tropa y los exponía a envenenamientos ${ }^{39}$.

\section{TENSIONES Y TRASFORMACIONES: LA EXPERIENCIA DE LOS VECINOS FRENTE AL ABASTECIMIENTO MILITAR.}

Isidro Vanegas interpreta el proceso revolucionario neogranadino como una trasformación generada por la sustitución de un régimen monárquico por uno republicano ${ }^{40}$. Dentro de las distintas innovaciones producidas en el desarrollo de la revolución, la militarización de la sociedad y su impacto económico provocaron mutaciones en las experiencias vitales de la población que padeció el costo de financiar la alimentación de los ejércitos que se movilizaban dentro de los territorios. En la provincia de Popayán, la revolución desde el inicio fomentó disensos en la opinión que escalaron rápidamente a enfrentamientos armados que durante 1809 a 1824 desplazaron a cientos de militares que fueron abastecidos con recursos extraídos de las ciudades, parroquias, sitios y haciendas. La carestía en la ración y el pago para las tropas era una difícil situación para los oficiales que trataban de mantener la cohesión de las tropas para evitar que el hambre y las penurias animaran a los soldados a desertar; contar con los recursos era un factor que le daba tranquilidad a los oficiales. Por ejemplo, en 1821 Francisco de Paula Santander le informaba a Simón Bolívar que el general Valdés había recibido $\$ 20.000$ pesos para el sustento de las tropas acantonadas en Popayán y la instrucción de estimular con parte de este dinero la deserción en las tropas enemigas de las que se tenía información se encontraban desbastecidas ${ }^{41}$.

39 (Popayán, 6-8 de junio de 1822), ACC, Fondo Independencia. Militar MI-3J Sig. 6874. f1 r- 3v. José María Espinosa. Memorias de un abanderado; recuerdos de la Patria boba 1810 - 1819 (Bogotá: Editorial Minerva S. A.1936), 72-73.

40 Isidro Vanegas. "Revolución neogranadina: la feliz catástrofe" en El siglo diecinueve colombiano, ed. Isidro Vanegas (Bogotá: Ediciones Plural, 2017), 33- 36.

41 Luis Horacio Domínguez, Cartas Santander - Bolívar 1820 - 1822. Tomo III, (Bogotá: Fundación para la conmemoración del bicentenario del natalicio y el sesquicentenario de la muerte del general Francisco de Paula Santander, 1988), 64. 
La obligación de satisfacer las necesidades vitales de los ejércitos le dio lógicamente un carácter perentorio a la recolección y distribución de productos en cuyo ciclo fue involucrada la población que puede dividirse entre los que asumieron el pago de las contribuciones y los que fueron empleados por su autoridad u oficio en la tarea de abastecer los ejércitos. La militarización de la sociedad y el peso de mantener a los hombres en armas es también una posibilidad de acercarnos a observar los cambios que el abastecimiento militar propició en la vida de los contemporáneos. En esta última sección expondremos las tensiones entre la población y las nuevas experiencias sociales que el abasto trajo para los hacendados, mayordomos, proveedores y regidores.

Los vecinos y vecinas en las ciudades y parroquias de todos los estamentos quedaron en igualdad de condiciones frente a la autoridad militar que a través de la institucionalidad hizo extracciones de recursos para su abastecimiento. Por ejemplo, las panaderas y pulperas de Popayán durante la restauración monárquica estuvieron dentro de las listas de contribuyentes para saldar las exigencias de dinero hechas por Juan Sámano $^{42}$. Los hombres y mujeres de otros oficios como las modistas y los sastres fueron conducidos a la maestranza para la confección de los trajes del ejército mientras que los plateros fueron obligados a la elaboración de charreteras y hebillas de palta y algunos indígenas fueron sacados de sus territorios y obligados a llevar alimentos para los caballos de la tropa ${ }^{43}$. Otros habitantes fueron puestos al servicio directo de los ejércitos como leñadores, sirvientes y postas ${ }^{44}$. Todas estas disposiciones alteraron la vida dentro en la ciudad y el mundo rural que poco a poco se quedaba sin labradores incrementando la escasez de alimentos, una situación que obligó en 1817 al síndico procurador general del cabildo de Popayán a solicitar a las autoridades tomar disposiciones gubernativas que aliviaran el peso que el abasto militar impuso sobre la

44 (Popayán, 7 de septiembre de 1816), ACC, Libros Capitulares, t. 58, 1817 f. 39. 
población ${ }^{45}$.Tanto los sectores plebeyos como los más encumbrados de la sociedad estuvieron a merced de satisfacer del apetito militar.

Los mayordomos tenían competencias administrativas sobre las haciendas que pertenecían a propietarios que no residían en ellas, una situación que los obligó a responder las solicitudes de las autoridades y a estar informando constantemente a los dueños de las entregas que debían hacer. Las extracciones de 1816 en la hacienda de Laboyos en Timaná y la presión militar sobre el mayordomo Juan de Dios Perea explica en parte la carta que le envía al propietario Elías Tejada residente en Popayán: "los inconvenientes que tengo para no poder seguir en el cuido [sic] de la hacienda y suplicándole me alivie de esta presión y mande otro mayordomo a que reciba la hacienda." ${ }^{46}$. Elías Tejada aceptó la renuncia de su mayordomo acosado por las autoridades y en remplazo envió a Antonio Molina, que al pretender detener la expoliación de la hacienda de la que recientemente había sido encargado, recibió la siguiente nota: "entorpecer las ordenes a que debe dar un ciego cumplimiento, y evitar contestaciones y cavilosas excepciones: bajo lo expuesto debe estar usted advertido que, si el día que se le tiene prefijado no está en esta los treinta pesos, ira un comisionado a su costa a hacerlos efectivos, y no tendrá usted que reclamar quebrantos" ${ }^{47}$. La experiencia del mayordomo encargado del control y administración de la hacienda pasó a ser durante los años estudiados un oficio que acarreaba problemas con los militares y las autoridades lo que antes de la revolución era algo inédito.

La experiencia del hacendado sufrió iguales trasformaciones que dejaron a los dueños sin la posibilidad de disfrutar de la producción agrícola y ganadera. Las peticiones hechas a los oficiales para evitar el pago de empréstitos y capitaciones por lo general fracasaban e incluso trajo a los solicitantes consecuencias mucho más lesivas. Por ejemplo, el 26 de

45 (Popayán, 18 de julio de 1817), ACC, Libros Capitulares, t. 58, 1817f.37v.

46 (Timaná, 30 de marzo de 1816), ACC, Fondo independencia - Militar. Correspondencia. Sig. 4300 Ind. P I -1 v. f. $23 \mathrm{v}$.

47 (Timaná, 20 de marzo de 1819), ACC, Fondo independencia - Militar. Correspondencia. Sig. 4300 Ind. P I -1 v. f.19r. 
septiembre de 1817 en Popayán el cabildo determinó secuestrar todas las reses de Francisco Cabal para suplir la carestía de ganados ${ }^{48}$. Las extracciones hechas por los ejércitos de ambas sectores fueron igual de onerosas; el 6 de junio de 1820 en Toro, José Joaquín Hormaza lamentaba la hostilidad del comandante Warletta que no vacilaba en calificarlo como un "tirano", mucho más después de la exigencia que le hizo a la localidad de cuatro mil pesos recolectados a "punta de bayoneta cala$\mathrm{da}{ }^{\text {"49; }}$; situaciones como las anteriores llevaron a las haciendas a un drástico deterioro en su producción agropecuaria ${ }^{50}$. El proceso de abasto para los hacendados significó un cambio sustancial en la administración de estas posesiones agrarias. Las haciendas del Valle del Cauca no sólo se vieron afectadas por la extracción de ganados, sino también por la pérdida de su fuerza laboral, impulsando a estas unidades agrarias a tener que hacer una reconvención de sus tradicionales actividades económicas ${ }^{51}$. En tal sentido, el impacto del proceso de abasto implicó un giro en la experiencia del hacendado que debió introducir cambios en su producción y soportar los desajustes económicos provocados por las constantes extracciones.

Los proveedores, quienes se encargaron de coordinar la distribución del abasto fueron los nuevos funcionarios que entraron a participar con las antiguas instituciones de gobierno en la recolección y distribución de alimentos y vituallas. Su selección por lo general estuvo regida por la preferencia de los regidores de escoger vecinos acaudalados y rivales a su causa política. Por ejemplo, el cabildo monarquista de Popayán el 4 de enero de 1817 asignó como proveedor a José María Mosquera que durante 1814 había presidido el gobierno republicano de Popayán y había apoyado a Antonio Nariño ${ }^{52}$. El día que Mosquera fue notifi-

48 (Popayán, 26 de septiembre de 1817), ACC, Actas de Cabildo de Popayán para el año de 1817. t. 58, f.59r

49 (6 de junio de 1820), ACC, Fondo independencia - Militar. Correspondencia. Sig. 6718 Ind. CIII 2g. f. 1 r.

50 (Caloto, 3 de junio de 1822), ACC, Fondo independencia - Militar. Correspondencia. Sig. 1331 Ind. CI -15 cp. f. $2 \mathrm{r}-5 \mathrm{v}$. de historia social. German Colmenares, José Escorcia, Francisco Zuluaga (Bogotá: Instituto Colombiano de Cultura), 58.

52 (Popayán, 4 de enero de 1817), ACC, Libros Capitulares, t. 58, 1817, f.4v. 
cado, evadió el nombramiento alegando que ese día era día festivo ${ }^{53}$. Una estrategia que sólo fue viable ese día porque al siguiente quedo oficialmente facultado como proveedor. Mosquera, cinco meses después, hizo la solicitud de ser relevado pero el cabildo no aceptó la petición. $\mathrm{Al}$ año siguiente, el 7 de agosto de 1818 hizo un nuevo intento pidiendo la remoción del cargo que le fue aceptada y en su reemplazo, se escogió a Elías Tejada quien se opuso con distintos argumentos que finalmente no logaron disuadir al cabildo, que optó como última mediada, ponerlo en prisión hasta que aceptara asumir las tareas de proveedor ${ }^{54}$.

La economía de guerra hizo que la sociedad y sus autoridades quedaran subordinadas al poder militar que despreció los fueros corporativos, que antes de la revolución habían gozado de aceptación por parte de la población. En 1818 el regidor Agustín Velasco, que se encontraba desempeñando sus funciones de control en la carnicería pública, fue abordado por un soldado que le entregó una boleta firmada por el comandante español don Miguel Letamendi en la cual le ordenaba entregar quince libras de gordana que no se pudieron satisfacer debido a la poca grasa del ganado sacrificado ${ }^{55}$. Más tarde, el regidor fue apresado y llevado ante Letamendi, quien después de insultarlo lo golpeó con un garrote ordenando que llevaran al regidor por las tiendas de Popayán a comprar la gordana de su propio bolsillo ${ }^{56}$.

Don Agustín luego contó al cabildo lo que ya era públicamente conocido y éste reaccionó protestando como cuerpo de gobierno, señalando a los militares como autoridades que debían mantenerse en sus límites ${ }^{57}$. Esto motivaría reclamaciones ante el virrey, pues los excesos de los militares no se detenían y el abasto era cada vez más oneroso incrementando el estado de escasez en que se encontraba la ciudad y además, subordinaba a sus autoridades ante los jefes militares ${ }^{58}$. El procurador general en una representación ante el cabildo expuso la situación di-

53 (Popayán, 4 -7 de enero de 1817), ACC, Libros Capitulares, t. 58, 1817, f.4r - 5r.

54 (Popayán , 7 de agosto de 1818), ACC, Libros Capitulares, t. 59, 1818, f. 38r.

55 (Popayán, 27 de abril de 1815), ACC, Libros Capitulares, t. 57, 1816, f. 32v.

56 (Popayán, 4 de julio de 1817) ACC, Libros Capitulares, t. 58, 1817, f.33r.

57 (Popayán, 4 de julio de 1817), ACC, Actas de Cabildo para el año de 1817, t. 58., f. 33v.

58 (Popayán, 18 de agosto de 1817) ACC, Actas de Cabildo para el año de 1817, t. 58, f.38r. 
ciendo que "...pasando ya de la raya los ultrajes y conminaciones que a cada paso se hacen a todos los magistrados y aun al mismo cuerpo, sin manifestar hasta ahora las credenciales y embestiduras que detengan para procedimientos tan atropellados, descomedidos, e impolíticos, y muy ajenos de la jurisdicción militar" 59 .

La economía de guerra articulada al abasto de las tropas fue un eje sobre el que gravitó la sociedad de la provincia de Popayán la cual fue impactada en su producción y en las experiencias de la población que afrontaron las novedades bélicas. Muy distintas fueron las experiencias colectivas de la población antes y después de la revolución que afrontaron la militarización de la sociedad y las implicaciones que esta tuvo.

\section{Conclusiones}

El abastecimiento de los ejércitos es una ventana que permite ver los cambios que produjo la revolución y la guerra durante 1808 a 1824 en la provincia de Popayán. Los cambios de orden político impulsaron importantes modificaciones a la economía regional que quedó supeditada a las necesidades militares que las autoridades cargaron a los vecinos de todos los estamentos de la sociedad. La extracción de alimentos y vituallas no distinguió privilegios, fueros o estatus social, pues toda la población fue obligada a pagar de acuerdo a sus bienes y posesiones. Un sistema legal garantizó estas extracciones que fluyeron a través de un ciclo que incluyó diferentes instituciones y hombres de las localidades, todos subordinados al poder militar que reasignó funciones, determinó necesidades y coaccionó a la población para satisfacer perentoriamente los requerimientos de abasto. Un ciclo que no tuvo un funcionamiento ideal, lo que motivó que emergieran los conflictos entre los militares y el resto de autoridades involucradas en el proceso. En resumen, el abastecimiento de los ejércitos durante el periodo independentista configuró una nueva experiencia para la sociedad que afrontó la militarización, la guerra y el caro precio para alimentar y vestir cientos de hombres armados.

59 (Popayán, 7 de agosto de 1818) ACC, Actas de Cabildo para el año de 1818, t. 59, f. 38v. 


\section{Bibliografia}

\section{Fuentes Primarias}

Archivo Central del Cauca (ACC), Popayán-Colombia, Fondo Independencia.

Archivo Central del Cauca (ACC), Popayán-Colombia, Libros Capitulares.

Archivo Histórico de Cali (AHC), Cali-Colombia, Libros Capitulares.

Archivo Histórico Cipriano Rodríguez Santamaría (AHCRS), Chía-Colombia, Fondo David Mejía Velilla.

\section{Fuentes Secundarias}

Castaño P, Yoer J. "Alimentación y abastecimiento de víveres entre las tropas patriotas de la Nueva Granada, 1811-1816". Anuario de Historia Regional y de las Fronteras Vol. 9 No. 1 (2004): 95-112.

Díaz, Zamira. "Condiciones de la fuerza de trabajo hacia 1810-1830". En: German Colmenares, José Escorcia, Francisco Zuluaga. La independencia, ensayos de historia social. Bogotá: Instituto Colombiano de Cultura, 25-75.

Domínguez, Luis Horacio, Dr. Cartas Santander - Bolívar 1820 - 1822. Tomo III, Bogotá: Fundación para la conmemoración del bicentenario del natalicio y el sesquicentenario de la muerte del general Francisco de Paula Santander, 1988.

Espinosa, José María. Memorias de un abanderado; recuerdos de la Patria boba 1810 - 1819.Bogotá: Editorial Minerva S. A.1936.

Martínez Martín, Abel Fernando y Otálora Cascante, Andrés Ricardo. "Hambriento un pueblo lucha. La alimentación en los ejércitos del Rey y del Libertador durante la independencia de Colombia (1815-1819)". Historia Crítica, Nº. 41, 2010, 86-109.

Mazzeo, Cristina, "Pagando por la guerra: comercio y finanzas. Entre la independencia y la Guerra de la Confederación". En: Tiempo de guerra. Estado, nación y conflicto en el Perú, siglos XVII- XIX, editado por Carmen McEvoy y Alejandro M. Rabinovich. Lima: Instituto de Estudios Peruanos, 2018, 191- 212. 
Prado Arellano, Luis Ervin. “Organización y logística: los límites para la organización del ejército neogranadino en contienda”. Historia y Espacio, No 24, (2005), 1- 20.

Prado Arellano, Luis Ervin. "Esclavismo, consenso y rebelión en la costa pacífica neogranadina, 1810-1830, en El siglo XVIII americano, eds., Ana Catalina Reyes, Juan David Montoya, Sebastián Gómez González, (Medellín: Universidad Nacional de Colombia, sede Medellín, 2013), 255- 282.

Rabinovich M., Alejandro, Ser soldado en las guerras de Independencia. La experiencia cotidiana de la tropa en el Río de la Plata, 18101824. Buenos Aires, Random Hause Mondadori, 2013.

Vanegas, Isidro. "Revolución neogranadina: la feliz catástrofe.” En: Isidro Vanegas editor, El siglo diecinueve colombiano, Bogotá: Ediciones Plural, 2017.

Para citar este artículo: Prado Valencia, David Fernando y Valencia Colina, Christian Camilo. "Una carga para los pobladores y un desafió para las autoridades: el abastecimiento de los ejércitos en el suroccidente neogranadino durante las guerras de 1808-1824", Historia Caribe Vol. XV No. 36 (Enero-Junio 2020): 51-72 DOI: http://dx.doi. org/10.15648/hc.36.2020.4 